\title{
TRANSAMAZÔNICA: INTEGRAR PARA NÃO ENTREGAR
}

\author{
Matilde De Souza ${ }^{1}$
}

\begin{abstract}
RESUMO
Este artigo discute como o governo ditatorial do General Emílio Garrastazu Médici se utilizou de elementos simbólicos como base para a legitimação da grande empreitada da colonização da Amazônia. O objetivo é discutir, a partir dos conceitos de nação, civilização e conquista, como os esforços de ocupação e de desenvolvimento da região mobilizaram energias materiais e ideacionais para promover a ocupação da Amazônia. Esse processo se deu no âmbito do Programa de Integração Nacional, no qual a construção da rodovia Transamazônica teve grande relevo. Utilizando-se de fontes bibliográficas, documentais e materiais divulgados por alguns veículos da grande imprensa brasileira da época, o artigo mostra a mística da integração nacional elaborada a partir de alguns elementos simbólicos como o Eldorado, o paraíso, o inferno, o deserto verde, o vazio, a solidão. A metodologia utilizada foi análise documental e de discurso. A conclusão do artigo é que o Plano de Integração Nacional não reduziu o problema da seca nos sertões nordestinos, nem concluiu a integração nacional. Esta última permaneceu como propósito, juntamente com os projetos de colonização e as iniciativas de ocupação que ainda persistem.
\end{abstract}

Palavras-chave: Transamazônica. Integração Nacional. Ocupação da Amazônia.

\begin{abstract}
This article discusses how the dictatorial government of General Emilio Garrastazu Médici used symbolic elements as the basis for the legitimation of the occupation of the Amazon. The objective is to discuss, based on the concepts of nation, civilization, and conquest, how the occupation and development efforts of the region mobilized material and ideational energies to promote the occupation of the Amazon. This process took place within the scope of the National Integration Program, in which the construction of the Transamazon Highway was of great importance. Using bibliographic, documentary, and material sources disseminated by some vehicles of the great Brazilian press at the time, the article shows the mystique of national integration elaborated from some symbolic elements such as the Eldorado, the paradise, the hell, the green desert, the solitude. The methodology used was document and discourse analysis. The conclusion is that the National Integration Plan did not reduce the drought problem in the northeastern backlands, nor did it complete national integration. The latter remained as a purpose, along with the ongoing settlement projects and occupation initiatives.
\end{abstract}

Keywords: Transamazon. National Integration. Occupation of the Amazon.

Submetido em: 27.02 .2020

Aprovado em: 17.04 .2020

\section{INTRODUÇÃO}

Até os anos 1970 o processo de ocupação da Amazônia se amparou, dentre outros mecanismos, em elementos do imaginário social, tais como: a procura pelas Amazonas, a busca do paraíso e também do Eldorado. Esses elementos, que estavam presentes no período

\footnotetext{
${ }^{1}$ Doutora em Ciências Humanas: Sociologia e Política, UFMG. Professora da PUC Minas. Departamento de Relações Internacionais. E-mail: matilde@ pucminas.br
} 
colonial, também podem ser encontrados na época da economia da borracha (quando a Amazônia foi divulgada como manancial inesgotável de matérias-primas) e ainda nos anos 1970, quando a região era vista como terra prometida para os nordestinos sem-terra e assolados pela seca, "terra sem homens para homens sem terra", "deserto verde" a ser ocupado e explorado pelos habitantes do "deserto árido".

Naquela época a região foi propagandeada tanto como Eldorado quanto inferno verde, espaço aberto à ocupação e à transformação, um manancial que poderia alimentar a crescente população mundial e propiciar enormes riquezas a um país que aspirava grandeza e progresso. Nos anos 1970, a construção da rodovia Transamazônica foi um meio para promover a integração da Amazônia. A rodovia não chegou a ser concluída e permanece, ainda hoje, inacabada (GIOVANAZ, 2017).

Este artigo discute como o governo ditatorial do General Médici legitimou a grande empreitada de colonização da Amazônia, além de outras ações políticas de grande repercussão nacional, utilizando, para isto, de elementos simbólicos que podem ser identificados no esforço de catalisar energias, a partir do Programa de Integração Nacional (PIN) e da construção da rodovia Transamazônica, visando a conquista da região - o mistério, o Eldorado, o paraíso, o inferno, o deserto verde, o vazio, a solidão. Esses elementos foram expressos em alguns discursos e na propaganda oficial, publicados em veículos da grande imprensa da época (SOUZA, 1995). Para tal, nação, civilização e conquista compuseram o ideário que informou a produção de discursos e propaganda oficial, além de tecer parte da cobertura jornalística sobre o grande empreendimento nacional.

Diante disso, o presente estudo está organizado em 4 seções, à exceção da introdução e conclusão. Inicialmente apresenta-se, de forma breve, os conceitos de nação, integração e soberania. Entende-se que a busca por legitimidade da ação política por parte do governo ditatorial se ancorou na tentativa de conferir um sentido de carisma à ação de conquista da região. A segunda seção apresenta o PIN e a terceira, como uma complementação, acrescenta alguns aspectos da dinâmica política da época, para contextualizar a política de integração nacional e discorrer sobre a figura do Presidente, General Emílio Garrastazu Médici. Por fim, discute-se sobrea implantação do PIN, com foco para a construção da rodovia Transamazônica. Junto com outras iniciativas, essa rodovia compunha o Plano de Integração Nacional. A relevância está na possibilidade de sua exploração simbólica, por um governo 
ditatorial $^{2}$, no sentido de sua atratividade para mobilizar a população em torno de um feito grandioso ${ }^{3}$.

\title{
1 INTEGRAÇÃO: ASPECTOS CONCEITUAIS E SIMBÓLICOS
}

O Programa de Integração Nacional teve seu foco na construção da rodovia Transamazônica, tanto pelo aspecto econômico quanto simbólico. A grande obra humana que a construção da estrada representava foi utilizada para expressar esperança e mobilizar energias individuais e coletivas dos cidadãos de uma pátria que se sentia "ameaçada" por inimigos internos e externos. Tudo isso visando realizar a conquista de um "Mundo Novo", a ocupação do espaço, a remissão do inferno e sua transformação em paraíso - um paraíso criado pelos homens, a partir da conquista da natureza.

\begin{abstract}
A Amazônia imaginária tem importante e profunda imbricação com a Amazônia real, pois busca seus elementos tanto na "invenção" (GONDIM, 1994) da região, como em construções simbólicas da tradição laica e religiosa, e também, na própria natureza amazônica e em seus habitantes: floresta, rios, animais, populações autóctones. Ambas, a real e a imaginária, contêm laços que se diriam mágicos, além de outros, é claro, com o Brasil: região aberta à conquista e ao desvendamento do desconhecido, do mistério, tendo em vista a ocupação e exploração; Eldorado, que esconde inumeráveis riquezas; deserto a ser dominado e ocupado, povoado e civilizado; mundo aquático, desafio à obra humana que se realiza pelo trabalho. Ambas trazem elementos profundos para se pensar a política em âmbito nacional e a força necessária para a expansão econômica, no período contemplado, encontra aí sua raiz. No governo Médici a política de ocupação da Amazônia possuiu um caráter simbólico de conquista, simbolismo cujas fontes encontram-se na dimensão imaginária da Amazônia; os cidadãos comuns, imbuídos do desejo de progresso, alimentam o sonho do Eldorado e de alcançar a terra prometida, e partem para a obra de conquista, empurrando a fronteira econômica, expandindo o mercado e levando a "civilização para a selva". (SOUZA, 1995, p. 17).
\end{abstract}

O desafio da integração relaciona-se à ideia e à tarefa de construção da nação. Embora muitos estudiosos reconheçam a dificuldade de delimitar um conceito de nação (DALLARI, 1983; ROSOLILLO, 1992), tendem a concordar com a função simbólica que a ideia, muito embora fluida, adquire na consolidação do Estado Moderno enquanto instituição, cuja autoridade deve gozar de legitimidade para liderar o exercício do poder político (WEBER,

\footnotetext{
${ }^{2}$ O governo do General Emílio Garrastazu Médici foi herdeiro direto do AI-5, tendo recrudescido a repressão aos opositores do regime militar. Esse período também ficou conhecido como "anos de chumbo". Contudo, e apesar desse recrudescimento, o mesmo governo também buscou sua legitimação. Um dos mecanismos para isso foi o uso simbólico do Plano de Integração Nacional.

3 Soares (2014), ao discutir a complexidade desse período, assinala a busca do regime militar por sua legitimação, tratando a autoria como estratégia e o autor, General Médici, como uma invenção do regime. Tal estratégia de legitimação teria contribuído para a construção da identidade pessoal do Presidente e popularizado seus discursos junto à população, ampliando sua visibilidade.
} 
1982). O conceito de nação expressa a ideia de todo coeso, cujos contornos demandariam certo grau de identidade cultural, linguística, religiosa e outras, entre os seus membros.

Para Dallari (1983), o conceito de nação se desenvolve, historicamente, a partir da luta contra o absolutismo e pela soberania popular. Assim, a ideia é próxima do sentido de "comunidade", vis a vis o sentido de "sociedade" (WEBER, 2003). Desse modo, se os fundamentos do sentido de comunidade e de sociedade se interpenetram, o poder, que se estrutura no âmbito da sociedade, ou não se legitima, ou é exercido de modo precário, caso não haja um sentido de comunidade compartilhado pelos cidadãos. Entende-se que os recursos de estratégia e tática de que se reveste o exercício do poder, portanto, sua "bagagem" de racionalidade (REIS, 1984), não são despidos do conteúdo simbólico do qual este mesmo poder se cerca, no sentido do seu exercício legítimo. Tal exercício, dado o conteúdo simbólico, traz consigo elementos do carisma, ainda que se considerem os contornos de impessoalidade de que se reveste o domínio racional-legal (WEBER, 1982).

A ideia de integração nacional e de nação contém, como aspecto básico, a noção de todo orgânico, onde clivagens, divergências, conflitos, são postos em segundo plano, diante de algo maior que seriam, supostamente, os valores coletivos, materiais ou culturais. À ideia de nação agrega-se o conceito de soberania, que incorpora a dimensão da autoridade máxima do Estado sobre o território e o resguardo do poder nas mãos da autoridade política (KRITSHC, 2002). Tal autoridade lidera o processo de integração, do qual a modernização é aspecto importante. A soberania seria um poder desperto quando "é quebrada a unidade e a coesão social, quando existem concepções alternativas acerca da constituição, quando há ruptura na continuidade do ordenamento jurídico" (MATTEUCCI, 1992, p. 1184).

Nas sociedades em que a integração é um objetivo, é a ideia de nação que deve se consolidar, visto que:

Para obter maior integração de seu povo, e assim reduzir as causas de conflitos, os Estados procuram criar uma imagem nacional, simbólica e de efeitos emocionais, a fim de que os componentes da sociedade política se sintam mais solidários. Para tanto, busca-se evidenciar e estimular todos os elementos comuns que atuam como pontos de ligação entre os diferentes grupos sociais, especialmente procurando ressaltar os feitos positivos de cada grupo como realizações de todo o conjunto. E é por isso mesmo que se apregoa a existência de características nacionais, quando se apontam certas notas comuns a toda a sociedade política, pois isso favorece a formação de uma consciência de comunidade. Assim, a submissão a um governo comum, o uso da mesma língua, a aceitação de muitos valores culturais comuns, bem como a comunidade de interesses, tudo isso é insuficiente para fazer do Estado uma Nação, mas é útil para a obtenção de maior solidariedade na persecução dos objetivos da sociedade política. (DALLARI, 1986, p. 116. Grifos no original). 
A integração "significa a superação das divisões e rupturas e a união orgânica entre os membros de uma organização" (PASQUINO, 1992, p. 632). Trata-se, portanto, de uma integração sistêmica, na qual se buscam o equilíbrio e a harmonia do todo, ultrapassando o mero sentido de unificação. Necessitando de certa homogeneidade cultural para se efetivar, a integração também depende da certeza quanto ao acesso a benefícios e do impulso de uma elite na condução do processo. Assim, a integração territorial, passo decisivo na construção do Estado, visaria a unificação do mercado, do ordenamento jurídico, do sistema de transporte e do sistema tributário. Já a integração nacional "diz respeito ao processo de criação de uma identidade comum a todos os grupos étnicos, linguísticos, religiosos e regionais, a fim de que se sintam parte de uma mesma comunidade política" (PASQUINO, 1992, p. 633). Portanto, integração territorial e nacional se complementam. E é no conceito de integração nacional que as referências simbólicas se unificam (SOUZA, 1995).

\section{O PROGRAMA DE INTEGRAÇÃO NACIONAL}

A ideia de um programa de integração nacional foi ganhando força nos governos militares, com a motivação do desenvolvimento, da interiorização da economia e da integração da Amazônia (VEJA, No 29, 1969, p. 12; JORNAL DO BRASIL, 04/03/1969, p. 15). O Programa de Integração Nacional, "um projeto de alcance econômico de longo prazo, mas de capitalização política de curto prazo" (BETING, 1973, p. 251), foi criado pelo Decreto-Lei $\mathrm{n}^{\circ}$ 1.106, de 16 de junho de 1970 (BRASIL, 1970 C), com o objetivo de implementar obras de infraestrutura nas regiões norte e nordeste, visando promover sua mais rápida integração à economia nacional (PEREIRA, 1971). Em seu Art. $2^{\circ}$, o referido DecretoLei estabelece que "a primeira etapa do Programa de Integração Nacional será constituída pela construção imediata das rodovias Transamazônica e Cuiabá-Santarém” (BRASIL, Decreto-Lei No $1106 / 1970$, Art. $2^{\circ}$ ). Esse Decreto-Lei foi regulamentado pelo Decreto $N^{\circ}$ 67.113, de 26 de agosto de 1970, que definiu as atividades da primeira etapa do PIN:

Art. $1^{\circ}$ O Programa de Integração Nacional, criado pelo Decreto-Lei $n^{\circ} 1.106$, de 16 de junho de 1970, compreenderá especificamente, em sua primeira etapa, além das tarefas comuns de cada Ministério, necessárias ao pleno desenvolvimento do Programa, as seguintes atividades: I - na área do Ministério dos Transportes, a imediata construção das rodovias Transamazônica e Cuiabá-Santarém, bem como de portos e embarcadouros fluviais, com seus respectivos equipamentos; II - na área do Ministério da Agricultura, a colonização e a reforma agrária, mediante a elaboração, a execução de estudos e a implantação de projetos agropecuários e agroindustriais, com as competentes desapropriações; a seleção, o treinamento, o transporte e o assentamento de colonos; a organização de comunidades urbanas e rurais e respectivos serviços básicos; III - na área do Ministério do Interior, o aceleramento dos estudos e a implantação de projetos constantes da primeira fase do Plano de 
Irrigação do Nordeste, abrangendo obras de retenção, desvio, canalização, condução, aspersão e drenagem hidráulica, com prioridade para os que ofereçam, desde já, maior benefício social; IV - na área do Ministério das Minas e Energia, o levantamento topográfico, da cobertura florestal, da geomorfologia para pesquisas minerais e energéticas, da natureza do solo e da respectiva drenagem e umidade. (BRASIL, Decreto No. 67.113/1970).

O Decreto $\mathrm{N}^{\mathrm{o}}$ 67.557, de 12 de novembro de 1970, declarou prioritárias, para fins de Reforma Agrária, diversas áreas de terra nos vários estados Amazônicos, criou a Delegacia Regional da Amazônia, ligada ao Instituto Nacional de Colonização e Reforma Agrária, INCRA, cuja previsão de atuação compreendia o assentamento de 100 mil famílias, a criação de até 100 cooperativas, regularização dos títulos de propriedade rural em favor dos posseiros já fixados na área (BRASIL, Decreto No 67.557/1970).

No I Plano Nacional de Desenvolvimento, lançado em 1972, o espaço amazônico segue entendido como vazio, e "a efetiva integração da Amazônia ao processo de desenvolvimento econômico brasileiro será obtida através da ocupação efetiva e racional dos espaços vazios e pari passu, uma reformulação progressiva dos setores produtivos." (SUDAM apud NAHUM, 2012, p. 4).

\section{INTEGRAR PARA NÃO ENTREGAR}

Incorporada a um programa de governo, a noção de integração referia-se, inicialmente, a um problema quase restrito à geopolítica, refletindo a preocupação militar com a integridade política e territorial das regiões de fronteira, pela conservação da soberania nacional, a ocupação de espaços interioranos ditos vazios e o desenvolvimento econômico. O conceito de integração nacional se inseria na Doutrina de Segurança Nacional (ALVES, 1989), que preconizava a articulação entre desenvolvimento econômico e segurança interna e externa. Esse Programa foi a mola propulsora da política de integração e da chamada conquista da Amazônia.

\footnotetext{
A Amazônia, lembrou o Presidente Médici, é o mundo desabitado, enquanto o Nordeste é o mundo onde ocorre a explosão demográfica. Completam-se as duas regiões, aquela proporcionando o meio físico e esta a multidão colonizadora, ambas contribuindo para a criação da riqueza comum. (PEREIRA, 1971, p. xxiii).
}

"Parco em análise de custos e pródigo em apelos patrióticos", o PIN deveria ser encarado "não como um dogma patriótico, a ser perseguido com furor maometano, e sim como opção econômica" (MORAIS, GONTIJO \& CAMPOS, 1970, p. 108). A ideia de integração, como conceito que contribui para dar forma a uma nação, foi essencial ao Programa de Integração Nacional e pretendeu entregar ao povo um ideário e um projeto 
comuns, despertar sua coragem, liberar e alimentar sua energia (MORAIS, GONTIJO \& CAMPOS, 1970).

\begin{abstract}
Talvez nenhum outro país tenha a possibilidade que agora se apresenta ao Brasil: a de conquistar meio Brasil para os brasileiros, a de domar perto de 4 milhões de quilômetros quadrados, desafio tão grande como a epopeia do Oeste para os Estados Unidos. A mística do pioneiro, o romance da terra, o apelo do desconhecido - tudo isso, que levou o homem norte-americano do Atlântico ao Pacífico e do Cabo Kennedy à Lua, está levando agora o homem brasileiro do Sul para o Norte, do Leste para o Oeste, da civilização para a selva. (BETING, 1973, p. 251).
\end{abstract}

A civilização na selva sugere algumas consequências, dentre elas o desmatamento.

Essa história de "inferno verde" não existe mais. O Amazonas é hoje uma grande realidade econômica e uma das regiões brasileiras que oferece maior rentabilidade aos investimentos. Dezenas de projetos industriais, agrícolas, pecuários e de serviços básicos, aprovados pela SUDAM, já estão funcionando ou em fase de execução. Nós estamos plantando no Amazonas um novo tipo de floresta em que as árvores são chaminés. [...] O Amazonas é um novo mundo para os seus investimentos. (VEJA, $\mathrm{N}^{\mathrm{o}} 77,1970$, p. 15. Grifo da autora).

Embora o PIN incluísse outras ações governamentais, é com a Transamazônica que a concepção e a simbologia da integração ganham vida. "Ao decretar o Plano de Integração, o Presidente conjuga sua preocupação ante a pungência do drama das 'vidas severinas' [...] com o objetivo de criar símbolos e motivações para o esforço nacional” (MORAIS, GONTIJO \& CAMPOS, 1970, p.109). Estrategistas do regime militar já alertavam para a necessidade de construir obras de infraestrutura na região amazônica, bem como concluir as já iniciadas, pois:

\footnotetext{
A integração e o desenvolvimento das planícies interiores e da região amazônica são considerados necessários para todas as "manobras de segurança nacional", impondo que se dê especial atenção a estas regiões, por muito tempo negligenciadas e ainda vulneráveis à penetração. (ALVES, 1989, p. 49).
}

Anunciada a construção da estrada, o debate voltou-se para a sua viabilidade. A euforia instigada pela integração e ocupação da região estimulou presença de políticos, funcionários públicos e outros personagens alheios aos desafios da empreitada (SOUZA, 2015) e, em sua grande maioria, desconhecedores dos enormes impactos que ela traria à região. Interpelado por um senador, que lamentava a pressa da decisão, o então Ministro da Fazenda, Delfim Neto, respondeu: "muda-se o plano, senador, mas faz-se a estrada" (PEREIRA, 197, p. 134). Segundo Beting (1973, p. 252), o PIN, "simbolizado na atração quase cinematográfica da rodovia transamazônica", não era um projeto apenas de caráter econômico, já que: 
Nenhum empreendimento puramente econômico capaz de mudar a face de qualquer nação pode ser avaliado em termos estritamente econômicos. [...] A conquista da Amazônia não pode ser quantificada nem submetida a um calendário fixo. A Amazônia é o desconhecido, é uma empolgante aventura, capaz de despertar a vocação de grandeza de todo um povo. (BETING, 1973, p. 252).

A conquista da Amazônia, expressa no PIN e liderada pela autoridade política, só poderia ser levada a efeito com mobilização popular, na qual foi apresentada como obra de um povo, estimulado a desejar, a almejar ser uma nação. Materiais de propaganda e outros contribuíram para expressar a ideia de conquista: a canção que embalou os corações dos brasileiros na copa do mundo de futebol de 1970 e os slogans do governo do General Médici: "Integrar para não entregar" e "Brasil, ame-o ou deixe-o". A construção da Transamazônica foi apresentada como possibilidade de realização desse desejo de conquista.

[A rodovia,] aberta na solidão, na infinitude, no semidesconhecido da selva, surge como a possibilidade da travessia: do passado, da tradição, de um "estado de natureza", para o futuro, a modernidade, a história, a cultura; do semidesconhecido para o conhecido, codificado, relatado, civilizado. (SOUZA, 1995, p. 102).

Levar a "civilização para a selva" era tarefa para milhões de pessoas, implicando conquista do espaço e a consequente transformação da paisagem e da cultura. Tal tarefa exigiria a ação integradora para incluir a região no turbilhão do desenvolvimento, vencendo “a vertigem do vazio" (FOOT HARDMAN, 1991. p. 108). Assim, o complexo rodoviário denominado de Transamazônica já estava em estudo quando, em visita ao nordeste durante seca severa, o Presidente Médici decidiu implementá-lo. Ao apresentar uma solução para o drama da seca, no âmbito do PIN, a ideia de integração surge acompanhada de sua carga simbólica. E a liderança política foi fundamental nesse processo.

O General Emílio Garrastazu Médici assumiu a presidência da República em 1970. Mercadante assim apresenta o Presidente: "General de cavalaria, gaúcho de Bagé, 65 anos de idade, presidente da República há quatrocentos dias, muito de ouvir, pouco de falar, capaz de milagres como este de ser popular sendo, ao mesmo tempo, o chefe de um governo de exceção" (MERCADANTE, 1970, p. 10).

Como afirmaram Klein e Figueiredo (1978, p. 28), pelo fato de terem desaparecido “alguns traços típicos de um sistema de dominação legal”, o governo Médici necessitaria de alguns recursos carismáticos para alcançar sua legitimação. Em discurso proferido em 7 de outubro de 1969, o General Médici afirma ter resistido à sua indicação ao cargo, mas que aceitou afinal, porque foi considerado "capaz de manter coesas e unidas as Forças Armadas da Nação em torno dos ideais da Revolução de Março de 1964” (MÉDICI, 1970B, p. 9). Neste 
mesmo discurso, diz que seu governo se iniciaria "numa hora dificil", porque sabia o que sentia e pensava "o povo, em todas as camadas sociais, em relação ao fato de que o Brasil ainda continua longe de ser uma nação desenvolvida, vivendo sob um regime que não podemos considerar plenamente democrático" (MÉDICI, 1970B, p. 10).

No mesmo discurso citado, o General conclamou todos ao "jogo da verdade", a ser jogado a partir de um plano de ação nacional, pois “o povo não pode ser espectador. Tem de ser o protagonista principal" (MÉDICI, 1970B, p. 14), considerando que, numa era de tantos avanços tecnológicos e conquistas da civilização, seria inadmissível:

[...] que um país como o nosso não venha a registrar, também, realizações e êxitos na história da civilização. O Brasil é grande demais, para tão poucas ambições. E está a exigir dos seus filhos uma atuação que realmente corresponda à magnitude do seu território, bem como aos alevantados ideais das gerações que nos legaram esse imenso patrimônio. Uma atuação, enfim, que se eleve à altura dos incontidos sonhos da mocidade que se prepara para dirigi-lo e cuja meta não pode ser outra, senão o triunfo final na arrancada para o desenvolvimento econômico e social. (MÉDICI, 1970 B. p. 15).

Ao assumir a presidência da República, em seu discurso de posse intitulado "Mundo sem Fronteiras" (MÉDICI, 1970 B, p. 33), o General afirma ser, ele próprio, “a oferta e a aceitação" e, não se considerando a promessa, afirma querer ser "verdade e confiança, ser a coragem, a humildade, a união". Apresentando-se assim, destaca por instantes sua origem: "venho do campo, da fronteira, da família; venho do povo, da caserna; venho de minha terra e de meu tempo... Venho do minuano".

Dizendo-se filho do vento, que é símbolo de força e sinônimo de espírito (SCHLESINGER \& PORTO, 1983), o General recita seu “credo". Como "oferta", o ocupante do cargo se entrega à nação, aceitando a missão de governar o país e dirigir o processo de desenvolvimento. Como "homem da fronteira, creio em um mundo sem fronteiras entre os homens" (MÉDICI, 1970 B, p. 34). Crendo "no poder fecundante da liberdade", ele acredita "nas virtudes da disciplina, da ordem, da unidade de comando". Por isso, crê "nas messes do planejamento sistematizado", ações coordenadas e integradas, regidas "por um grande plano diretor". E convoca, assim, a vontade coletiva e a participação "de todos os que acreditam na compatibilidade da democracia com a luta pelo desenvolvimento" (MÉDICI, 1970 B, p. 36).

O General afirma ter pressa e o ritmo de crescimento da economia não satisfaz seu desejo de velocidade. "Urge acelerar o processo", pois ele pensa "nas vidas que virão... nas dores futuras... no século que vai nascer" (MÉDICI, 1970 B, p. 37). Ao final do discurso, o General reitera sua fé nas bênçãos de Deus, que o levam a crer: 
[...] nos milagres que os homens fazem com as próprias mãos. E nos milagres da vontade coletiva. Creio na humanização da vida dos severinos do campo. E na solidariedade da família brasileira. Creio na alma generosa da mocidade. Creio na minha terra e no meu povo. Creio na sustentação que me haverão de dar os soldados como eu. Creio no apressamento do futuro. [...] E creio na missão de humanidade, de bondade e de amor que Deus confiou à minha gente. E, porque o creio, e porque o sinto, no arrepio de minha sensibilidade, é que, neste momento, sou a oferta e a aceitação. (MÉDICI, 1970 B, p. 39).

O Presidente articula em seus discursos elementos que poderiam ser atribuídos a alguém imbuído do "dom da graça” (WEBER, 1982): alguém capaz de guiar o povo na travessia, do deserto à "terra prometida"; um homem inspirado por Deus: "Agradeço a Deus a inspiração de fazer esta viagem..." (MÉDICI, 1970 C, p. 71), considerando-se dono de uma sensibilidade peculiar para ver e sentir o drama dos seres humanos abandonados ao seu próprio destino, ele afirma:

Aqui vim para ver, com os olhos da minha sensibilidade, a seca deste ano, e vi todo o drama do Nordeste. Vim ver a seca de 70 e vi o sofrimento e a miséria de sempre. [...] Vim ver e Vi. [...] Vi o homem. Falei a esse flagelado. Vi seus farrapos, apertei a sua mão... [...] Vi o sofrimento de homens moços... (MÉDICI, 1970C, p. 71).

O General toma decisões, imediatamente, no corpo do próprio discurso citado, e anuncia que irá "incentivar a programação de colonização em zonas úmidas do Nordeste, do Maranhão, do Sul do Pará, do Vale do São Francisco e do Planalto Central, de forma a absorver as populações de áreas consideradas totalmente desaconselháveis à vida humana" (MÉDICI, 1970 C, p. 76). Para esta realização, o General não apenas convoca: "Exijo a contribuição da Nação inteira[...]. Exijo a austeridade de todos os homens responsáveis, para que não haja indiferença ao sofrimento e à fome. Exijo que se diga e que se mostre sempre a verdade, por mais que ela nos doa" (MÉDICI, 1970 C, p. 77). E, após conclamar à colaboração a imprensa e os jovens, e apelar para a consciência nacional, invoca, mais uma vez, a ajuda divina: "quero dizer que não me sinto com poderes e dons para fazer milagres, mas tenho firmeza, confiança e decisão para proclamar à Nação inteira que, com a ajuda de todos os brasileiros e com a ajuda de Deus, o Nordeste haverá de mudar" (MÉDICI, 1970 C, p. 77). 


\section{A TRANSAMAZÔNICA}

Nestas margens do Xingu, em plena selva Amazônica, o Senhor Presidente da República dá início à construção da Transamazônica numa arrancada histórica para conquista e colonização deste gigantesco mundo verde - Altamira. 9-outubro-70. $\left(\right.$ VEJA, no 213,1972, p. 18) ${ }^{4}$.

As obras de construção da rodovia tiveram início em $1^{\circ}$ de setembro de 1970, inaugurando o empreendimento de "colonização" da Amazônia, rumo ao desconhecido da selva. Médici tinha pressa em "ajudar o homem a ajudar-se a si mesmo" (MÉDICI, 1970 B, p. 38). Os planos iniciais eram de construir, simultaneamente, as rodovias Transamazônica e Cuiabá-Santarém. Além disso, a cada $100 \mathrm{~km}$ de estrada estava projetada a construção de "núcleos básicos para o nascimento de 20 cidades na selva. A tarefa é tão imensa quanto generosos são seus objetivos propostos". (VEJA, n 104, 1970, p. 28).

$\mathrm{E}$ as ações do que se chamou "conquista" da Amazônia serviram como tronco integrador dos nacionais, conclamando o país a partir de slogans e textos de canções que se tornaram muito populares. A propaganda foi elemento fundamental em todo esse processo de produção da coesão nacional e promoção de "uma visão otimista dos brasileiros sobre o regime, baseada na crença de que o país seria uma das grandes potências mundiais" (BRAGA e SOUZA, 2019, p. 176) ${ }^{5}$. Além da propaganda oficial, dentre os slogans veiculados à época, notam-se: "ninguém segura este país"; "Brasil, ame-o ou deixe-o". Dentre as canções é pertinente registrar as seguintes: "Este é um país que vai pra frente"; "Pra frente Brasil"; "Você também é responsável"; "Eu te amo meu Brasil". Esse era um ambiente ao qual se buscou prover um clima de euforia, onde fazia parte o chamado "milagre econômico". Segundo reportagem da revista Realidade ( $\left.n^{\circ} 54,1970\right)$, um clima de ufanismo tomou conta do país. Após citar vários exemplos de tal manifestação, a reportagem afirmava que:

Mais do que tudo isto, há a exaltação ruidosa de alguns fatos: o início da estrada ciclópica que rasgará a Amazônia, abrindo-a de vez para a colonização; a cuidadosa preparação de atletas para a conquista de um lugar honroso nas próximas Olimpíadas; a festejada declaração de soberania sobre as 200 milhas oceânicas; a onda de confiança e orgulho que acompanha o jovem Emerson Fittipaldi nas pistas europeias [...]. (REALIDADE, $\mathrm{n}^{\circ} 54,1970$, p. 99.)

\footnotetext{
${ }^{4}$ Placa de inauguração do início das obras de construção da Rodovia Transamazônica. Imagem publicada pela Revista Veja, conforme as referências já informadas no texto.

5 É da mesma época o chamado "milagre econômico". A própria alusão a "milagre” contribui para compor o conjunto dos elementos simbólicos, vários deles de cunho religioso, que alimentou a propaganda oficial nesse período. Infelizmente, o espaço do artigo não permite ampliar a análise enveredando por mais essa trilha.

${ }^{6}$ As letras de todas essas músicas, bem como os respectivos compositores e intérpretes, podem ser encontradas no sítio vagalume.com.br.
} 
Giscard d'Estaing, então Ministro da Fazenda da República Francesa, considerou “a conquista da Amazônia como o "oitavo trabalho de Hércules"' (VEJA, no 161, 1971, p. 25). Héracles, ou Hércules, seria "o representante idealizado da força combativa [...]" e encarnaria “o ideal viril helênico [...] algo que só pertence ao céu”. (CHEVALIER \& GHEERBRANT, 1993, p. 486). O desenvolvimento era considerado "a grande missão do governo" (REALIDADE, $\mathrm{n}^{\circ}$ 54, 1970, p. 99), palavra que deveria sair da linguagem dos economistas e cair na boca do povo, pois "tudo se fundamenta no desenvolvimento, na integração nacional e na defesa do interesse nacional” (REALIDADE, $n^{\circ}$ 54, 1970, p. 101).

Eliseu Resende, naquela ocasião diretor do Departamento Nacional de Estradas de Rodagem, DNER, foi claro ao afirmar que a rodovia não teria prioridade econômica, mas deveria permitir a entrada de contingentes populacionais nordestinos na região. O projeto foi definido como pioneiro, e a estrada considerada:

\footnotetext{
[d]elineadora da maior horizontal brasileira, lugar geométrico dos mais distantes pontos de influência do Amazonas, vereda aberta ao nordestino para colonização do enorme vazio demográfico, conectando "estradas que caminham", integrando modalidades de transporte, harmonizando o desenvolvimento nacional. (RESENDE, 1969, p. 103).
}

A política rodoviária do governo no período privilegiou, em grande medida, a ligação das áreas de fronteira e, além disso, buscou abrir caminhos de ingresso para as regiões com menor densidade demográfica. As rodovias Cuiabá-Santarém e Transamazônica, cujo traçado se embrenham na floresta, são destaques.

O percurso da rodovia Transamazônica corta longitudinalmente praticamente todo o norte do Brasil, iniciando-se na cidade de Cabedelo, na Paraíba e projetada para chegar à cidade de Lábrea, no estado do Amazonas. A perspectiva era unir povoados e cidades que antes se comunicavam somente por via fluvial. A intervenção desencadeada na região transformou a paisagem, os povos, a cultura. Em texto de propaganda, a Superintendência de Desenvolvimento da Amazônia, SUDAM, exprimiu o sentido do progresso:

A Amazônia que você aprendeu na escola não existe mais. Hoje, você procura uma aldeia de índios e encontra uma fábrica. Ou uma fazenda moderna. Onde só tinha mato 10 anos atrás, agora você pode morrer atropelado... Mais da metade das estradas hoje em construção começa ou termina na Amazônia (VEJA, nº 132, 1971, p. 8). 
Autoridades governamentais afirmavam que a "Transamazônica é uma decisão política do Governo brasileiro". Como decisão política, tanto a construção da estrada, como o próprio Programa de Integração Nacional tem importância fundamental:

[...] por seu alcance ao mesmo tempo econômico, político e social... é uma longa caminhada que, como toda caminhada, haverá de começar com o primeiro passo. A proposta da Transamazônica é o primeiro passo de um projeto que não se restringe a uma simples abertura inconsequente de uma estrada na selva bruta, mas sim, representa o mais ambicioso programa de colonização de território e alargamento de fronteiras econômicas do mundo moderno. (BETING, 1973, p. 252).

O PIN foi visto como uma ousada decisão visando à unificação nacional, como mostra o apoio ao Programa, manifestado por Theobaldo de Nigris, à época presidente da Federação das Indústrias do Estado de São Paulo, FIESP, em recepção a Costa Cavalcanti, Ministro do Interior:

O Programa de Integração Nacional [...] constitui, sem favor algum, um trabalho de gigantes, o qual ficará assinalado em nossos fatos históricos de forma indelével. Ousamos até mesmo afirmar que na vida de nosso querido País será um marco, fulgurante indicativo de um brilhante período que se iniciará com a implantação do Plano de Integração Nacional [...]. "essa iniciativa constituirá autêntica epopeia brasileira, arrancada e ato de império, de afirmação, de posse e de soberania sobre uma região que se sabe ser das melhores aquinhoadas [...] É realmente um Programa de Integração Nacional e, mais ainda, um Plano de União Nacional, de brasileiros de pontos extremos, deste País de dimensões continentais. Juntos, os do Nordeste, do Norte, do Centro e do Sul, promoverão a ocupação e a exploração de cerca de dois terços do território brasileiro, até agora à espera da fecundação pelo trabalho de todos, que gerará também riqueza para todos. (NIGRIS, apud PEREIRA, 1971, p. 386).

O trabalho de gigantes, que a abertura da estrada mobilizava, não deveria se ocupar de questões de outra natureza. Afinal, como "terra prometida",

[...] a Amazônia poderia sobreviver sem boa parte de suas matas (a SUDAM exige que sejam preservados $50 \%$ das matas em seus projetos) como ainda se transforme, num prazo relativamente curto, numa nova terra prometida, graças a empreendimentos respaldados em grandes grupos financeiros. (VEJA, $n^{\circ} 266,1973$, p. 67).

Sem nenhuma sensibilidade ecológica, para não falar de desinformação científica, havia também quem, ao defender a Amazônia como celeiro do mundo, afirmasse que a região:

[...] será totalmente um paraíso terrestre, no futuro, no dia em que o cientista conseguir a auto-aniquilação de insetos destruidores e portadores de doenças, por meio da esterilização química. Exterminação de mosquitos, moscas caseiras, moscas de frutas, formigas e outros, que representam as principais pragas da região. (SILVA, 1971, p. 291). 
Registra-se, também, a proposta de uso de desfolhantes químicos para acelerar os trabalhos de desmatamento nas áreas das rodovias Cuiabá-Santarém e Transamazônica:

\begin{abstract}
Uma das vantagens dos desfolhantes é que quase todos os troncos de árvores resistem à perda artificial da folhagem, conservando seu valor comercial... Quanto à ecologia da zona tratada - esse não seria o problema da Transamazônica, segundo os técnicos, uma vez que a própria existência da estrada provocaria alterações marcantes - os efeitos registraram-se muito mais pelo brusco equilíbrio resultante da modificação do habitat pelo envenenamento indireto do terreno, o que pode ser remediado pelas chuvas. As alterações maiores são provocadas pelo súbito desaparecimento de insetos, frutas, folhagens e sementes, o que induz a fauna a emigrar. (PEREIRA, 1971, p. 246).
\end{abstract}

Não se tratava apenas de construir uma rodovia, mas, através dela, promover o sentimento de nação que amparasse a legitimidade da liderança política, implantar um modelo de ocupação, ritmo e orientação do processo de modernização, uma determinada ideia de progresso.

Enquanto o mundo se estraçalha por meio palmo de terra árida, com populações aflitas e abundantes lutando pelo pão miserável, só alucinados completos poderiam imaginar que o Brasil se daria ao luxo de conservar virgem a Amazônia, intocado seu solo, desconhecidas suas riquezas, desolados seus vazios imensos, na mais cretina das aberrações. Um país que não consegue ser dono de si mesmo, como imaginar possível comandar seu destino? [...] O homem na pública intimidade com a Lua, e o Brasil, em fatias, desconhecido de seus filhos que o vislumbram apenas pela cansada literática prima-irmã de vociferantes exaltações primárias. [...] Preservá-la [a Amazônia] é ocupá-la por brasileiros, no interesse da Nação. Não é louvar suas riquezas que ninguém conhece, nem exaltar potencialidades que a mata densa encobre. É cruzar a região de estradas, em primeiro lugar, e depois é [ocupála] com o nacional mesmo, o tal, antes de tudo um forte, capaz de plantar em um planalto abandonado uma cidade em três anos. (PINHEIRO NETO apud PEREIRA, 1971, p. 382).

Assim, o espírito do pioneirismo se revestiria do investimento produtivo, e o paraíso poderia existir para quem quisesse e pudesse investir, incrementado pela política de incentivos fiscais, conforme texto de propaganda oficial:

Antigamente se chamava inferno verde, e não tinha nada do que tem hoje. Agora, mais de 3,2 bilhões de cruzeiros estão sendo aplicados em quase 500 projetos agropecuários e industriais já aprovados pela SUDAM. Um verdadeiro paraíso para quem quer investir. Indústrias trabalham dia e noite. Produzem cimento, derivados de petróleo, produtos farmacêuticos, gêneros alimentícios, artefatos de borracha, embarcações, bebidas, sorvetes, plásticos, tecidos. Mineram jazidas de manganês, ferro, estanho, ouro. Exploram 3 milhões de quilômetros quadrados de matas de madeira de lei e 1.500 quilômetros de costas ricas em pescado... (VEJA, $\mathrm{n}^{\circ}$ 136, 1971, p. 54). 
Certamente, "o plano [de Integração Nacional] representa a conquista de um novo país, dentro da nação brasileira. [...] Nós vamos empurrar a fronteira para a conquista de um novo País” (DELFIM NETO apud MORAIS, GONTIJO \& CAMPOS, 1970, p. 56).

Em outubro de 1971, o Presidente Médici visitou as obras da Transamazônica, inspecionando as frentes de trabalho em "Itaituba, às margens do rio Tapajós, o centro pioneiro de colonização em Altamira, às margens do rio Xingu e o primeiro trecho inaugurado, de 252 km, em Marabá" (VEJA, n 161, 1971, p. 25). Na visão de progresso propagandeada à época, haveria uma contraposição entre a vida na selva, vida que seria dura, insalubre, solitária, sem a possibilidade do desfrute das benesses do desenvolvimento, e a vida urbana, dita civilizada, sendo civilização limitadamente entendida pelo seu aspecto econômico (SOUZA, 1995).

Neste sentido, a Amazônia, "último grande desafio à espera do homem" (VEJA, no 165, 1971, p. 16), estaria recebendo o remédio de que sempre precisara, na linguagem da propaganda oficial, ou seja, "dinheiro e tecnologia" (VEJA, n 181, 1972, p. 42). A chegada da civilização também deveria tirar a região e as pessoas do isolamento, considerado "o maior problema da Amazônia e tem a vastidão de seu contorno. A falta de comunicação, a dificuldade de contatos com a civilização, o primitivismo da vida na selva fazem do homem do interior um desprotegido [...]". (JORNAL DO BRASIL, 24/03/1969).

Elementos que seriam comuns da vida local vão se aglutinando e, aos poucos, formando uma corrente de opinião pública em prol da integração da Amazônia. O Presidente da República já havia solicitado a ajuda de tantos quantos pudessem se sensibilizar, no sentido de ajudá-lo "a ajudar o homem a ajudar-se a si mesmo". Assim, a construção da rodovia permitiu a corrida à região, o que contribuiu para a mudança tão esperada.

A estrada lá está, inacabada. Porém, a seu tempo, a estrada cumpriu certo propósito de estímulo à integração nacional, ao desenvolvimento de certo sentido de nação. Ela também proporcionou que a conquista e a chamada colonização avançassem à época e que continuassem avançando sertão adentro. Os tempos são outros, possivelmente a integração nacional e a construção da nação não estejam mais em perspectiva, mas, decerto, os desejos e os interesses dominantes sobre a região não tenham mudado substantivamente. Nos dias atuais, talvez não seja mais necessário lançar mão do imaginário social para construir a legitimidade desse processo. Contudo, essa já é uma outra história. 


\section{CONCLUSÃO}

A Rodovia Transamazônica foi praticamente abandonada logo depois de inaugurada. As motivações que estimularam a sua construção parecem ter se esvaído na travessia do último rio de trecho construído, mas deixaram conflitos individuais e coletivos que chegaram ou que se intensificaram com a estrada. O PIN não resolveu o problema dos milhares de nordestinos assolados pela pobreza e pela seca. A integração permaneceu como propósito, juntamente com os projetos de colonização e as iniciativas de ocupação, exploração e modernização da região.

O sentido de nação demanda estabilidade de uma identidade nacional, sendo, portanto, matéria permanente da sociedade e da autoridade política. Esse processo continua e governos recentes têm elaborado e mantido planos de integração, com o intuito de produzir uma integração intrarregional (Ministério da Integração Nacional/SUDAM, 2012). Além disso, intensificam-se o desmatamento, a exploração predatória e a ocupação do território.

São diversas as consequências desse processo, a maioria delas não foi contemplada neste breve artigo. Todavia, objetivou-se mostrar como os esforços de ocupação e desenvolvimento da região mobilizaram energias materiais e ideacionais para promover o que se entendeu, à época, como o gigantesco trabalho de "desbravamento" da floresta e exploração econômica dos recursos da região. A construção da Transamazônica, objeto mais visível da política de integração nacional dos anos 1970, obteve relativo sucesso quanto ao apoio popular que a iniciativa demandava, considerando que a autoridade política se investiu de carisma, constituído a partir da manipulação de um conjunto de elementos simbólicos que conjugava a construção de uma identidade nacional, a civilização e o desejo de conquista do desconhecido - a natureza amazônica.

\section{REFERÊNCIAS}

ALVES, Maria Helena Moreira. Estado e Oposição no Brasil -1964-1984. 5 ed. Petrópolis: Vozes, 1989.

BERMAN, Marshall. Tudo que é sólido desmancha no ar. São Paulo: Companhia das Letras, 1987.

BETING, Joelmir. "Política Econômica - O Desenvolvimento Econômico e a Integração Econômica Setorial e Nacional". In WIEDEMANN, Gen. Luiz Fellipe da S. (org.) Brasil: Realidade e Desenvolvimento. São Paulo: Sugestões Literárias, 1973.

BRASIL. Decreto No 67.113, de 26 de agosto de 1970. Regulamenta o Decreto-lei no 1.106, de 16 de junho de 1970, que instituiu o Programa de Integração Nacional. Brasília: Câmara 
dos Deputados. 1970 A. Disponível em: http://www2.camara.leg.br/legin/fed/decret/19701979/decreto-67113-26-agosto-1970-408679-publicacaooriginal-1-pe.html. Acesso em: 02. jan. 2019.

BRASIL. Decreto No 67.557, de 12 de novembro de 1970. Dispõe sobre a criação de área prioritária ao longo da rodovia Transamazônica, para fins de Reforma Agrária, a ser incluída no Plano de Integração Nacional, e dá outras providências. Brasília: Câmara dos Deputados, 1970 B. Disponível em: http://www2.camara.leg.br/legin/fed/decret/1970-1979/decreto67557-12-novembro-1970-409139-publicacaooriginal-1-pe.html. Acesso em: 05 jan. 2019.

BRASIL. Presidência da República. Casa Civil. Decreto Lei No 1106, de 16 de junho de 1970. Cria o Programa de Integração Nacional, altera a legislação do imposto de renda das pessoas jurídicas na parte referente a incentivos físcais e dá outras providências. Brasília: Presidência da República, 1970 C. Disponível em: https://www.planalto.gov.br/ccivil_03/decretolei/1965-1988/Del1106.htm. Acesso em: 09. jan. 2019.

BRASIL. Ministério da Integração Nacional. Superintendência do Desenvolvimento da Amazônia. Programa de Integração Intrarregional da Amazônia: Diagnósticos e projetos. Belém, 2012. Disponível em:

http://www.sudam.gov.br/conteudo/menus/referencias/biblioteca/arquivos/sudam2012/CAF11177_COD1007/Programa_Integracao_Intrarregional_Amazonia.pdf. Acesso em: 12. jan. 2019.

CHEVALIER, Jean \& GHEERBRANT, Alain. Dicionário de Símbolos. 7 ed. Rio de Janeiro: José Olympio, 1993.

DALLARI, Dalmo de Abreu. Elementos de Teoria Geral do Estado. 17 ed. São Paulo: Saraiva, 1983.

FOOT HARDMAN, Francisco. Trem Fantasma: A Modernidade na Selva. São Paulo: Companhia das Letras, 1991.

GIOVANAZ, Daniel. Transamazônica, 45 anos. In Amazônia, notícia e informação. 20 de novembro de 2017. Disponível em: http://amazonia.org.br/2017/11/transamazonica-45-anossobre-madeira-clandestina-e-ouro-para-ingles-ver/. Acesso em: 05 jan. 2019.

GONDIM, Neide. A Invenção da Amazônia. São Paulo: Marco Zero, 1994.

JORNAL DO BRASIL. Lira diz que Exército se transforma com a Nação. Rio de Janeiro, 04/03/1969. P. 15. Laboratório de Estudos do Tempo Presente. Acervo do Jornal do Brasil disponível na Internet. 1891-1999. Disponível em:

https://news.google.com/newspapers?nid=0qX8s2k1IRwC\&dat=19690304\&printsec=frontpa ge\&hl=pt-BR. Acesso em 05. jan. 2019.

JORNAL DO BRASIL. Isolamento da Amazônia. Rio de Janeiro, 24 de março de 1969. Laboratório de Estudos do Tempo Presente. Acervo do Jornal do Brasil disponível na Internet. 1891-1999. Publicação não disponível no referido acervo.

KLEIN, Lúcia; FIGUEIREDO, Marcus. Legitimidade e coação no Brasil pós-64. Rio de Janeiro: Forense Universitária, 1978. 
KRITSCHI, Raquel. Soberania: a construção de um conceito. São Paulo: Humanitas FFLCH/USP: Imprensa Oficial do Estado. 2002.

MARTINS, Edilson. Amazônia, a última fronteira. Rio de Janeiro: Codecri,1981.

MATTEUCCI, Nicola. “Soberania”. In BOBBIO, Norberto; MATTEUCCI, Nicola \& PASQUINO, Gianfranco. Dicionário de Política. 4 ed. Brasília, DF: Editora da Universidade de Brasília, 1992.

MÉDICI, Emílio Garrastazu. "Discurso de Recife". In TAMER, Alberto. Transamazônica: solução para 2001. Rio de Janeiro: APEC, 1970 A.

MÉDICI, Emílio Garrastazu Presidente. O Jogo da Verdade. s/ed., 1970 B. Disponível em http://www.biblioteca.presidencia.gov.br/publicacoes-oficiais/catalogo/medici/o-jogo-daverdade/@@download/file/O\%20Jogo\%20da\%20Verdade.pdf. Acesso em: 06. jan. 2019

MÉDICI, Emílio Garrastazu. Visão do Nordeste. Pronunciamento Do Presidente Médici, no encerramento da reunião do Conselho Deliberativo da SUDENE, em Recife, a 6-61970. Presidência da República. Casa Civil. Biblioteca da Presidência da República. Disponível em: http://www.biblioteca.presidencia.gov.br/presidencia/ex-presidentes/emiliomedici/discursos/1970/15 1970 C. Acesso em: 08. jan. 2019.

MERCADANTE, Luiz Fernando. Este é o Presidente. In Realidade. Edição 57. Dezembro de 1970. São Paulo: Abril, 1970. P. 08. Biblioteca Nacional. Hemeroteca Digital Brasileira.

Disponível em http://memoria.bn.br/pdf/213659/per213659_1970_00057.pdf. Acesso em: 07. jan. 2019.

MORAIS, Fernando; GONTIJO, Ricardo \& CAMPOS, Roberto de Oliveira.

Transamazônica. São Paulo: Brasiliense, 1970.

NAHUM, João Santos. Região e representação: a Amazônia nos planos de desenvolvimento. In Revista Bibliográfica de Geografía Y Ciencias Sociales. Barcelona: Universidad de Barcelona. Vol. XVII, $n^{\circ}$ 985, 25 de julho de 2012. Disponível em: http://www.ub.edu/geocrit/b3w-985.htm. Acesso em: 10. jan. 2019.

PASQUINO, Gianfranco. "Integração". In BOBBIO, Norberto; MATTEUCCI, Nicola \& PASQUINO, Gianfranco. Dicionário de Política. 4 ed. Brasília, DF: Editora da Universidade de Brasília, 1992.

PEREIRA, Osny Duarte. A Transamazônica: prós e contras. Prefácio de Arthur César Ferreira Reis. 2 ed. Rio de Janeiro: Civilização Brasileira, 1971.

REALIDADE. O novo ufanismo. Edição 54, setembro de 1970. São Paulo: Abril, 1970. Biblioteca Nacional. Hemeroteca Digital Brasileira. Disponível em: http://memoria.bn.br/pdf/213659/per213659_1970_00054.pdf. Acesso em: 03.fev.2019.

REIS, Fábio Wanderley. Política e Racionalidade. Problemas de Teoria e Método de uma Sociologia "Crítica” da Política. Belo Horizonte: UFMG/PROED/RBEP, 1984. 
RESENDE, Eliseu. "O papel da Rodovia no desenvolvimento da Amazônia". In JORNAL DO BRASIL: Revista Econômica do JB. Rio de Janeiro, 28 de março de 1969, pág. 103. Laboratório de Estudos do Tempo Presente. Acervo do Jornal do Brasil disponível na Internet. 1891-1999. Disponível em: https://news.google.com/newspapers?nid=0qX8s2k1IRwC\&dat=19690304\&printsec=frontpa ge\&hl=pt-BR. Acesso em 05. jan. 2019.

ROSSOLILLO, Francesco. "Nação". In BOBBIO, Norberto; MATTEUCCI, Nicola \& PASQUINO, Gianfranco. Dicionário de Política. 4 ed. Brasília, DF: Editora da Universidade de Brasília, 1992.

SCHLESINGER, Hugo \& PORTO, Humberto. Crenças, Seitas e Símbolos Religiosos. São Paulo, Paulinas: 1983.

SILVA, Renato Ignácio da. Amazônia: Paraíso e Inferno. 2 ed. São Paulo: Quatro Artes Editora, 1971.

SOUZA, César Martins de. Morte, saúde e ditadura na construção da Transamazônica. In Tempos Históricos. Vol. 19, $2^{\circ}$ semestre de 2015, p. 65-91. Disponível em: http://erevista.unioeste.br/index.php/temposhistoricos/article/view/12702. Acesso em: 03.fev.2019.

BRAGA, Magno M. Marçal; SOUZA, César Martins de. Transamazônica: terra, trabalho e sonhos. In Revista Territórios \& Fronteiras. Cuiabá, Vol. 12, nº 1, jan-jul., 2019.

Disponível em:

http://www.ppghis.com/territorios\& fronteiras/index.php/v03n02/article/view/898. Acesso em: 05. jan. 2019.

SOUZA Matilde de. A Epopeia da Transamazônica: 90 milhões em ação. 1995.

Dissertação (Mestrado em Ciência Política). Belo Horizonte: Programa de Pós-graduação em Ciência Política/UFMG, 1995.

VEJA. Presente e futuro do governo. Edição nº 29, de 23/06/1969. São Paulo: Abril, 1969. P. 12-16. Acervo digital. Disponível em:

https://acervo.veja.abril.com.br/\#/edition/34527?page=1\&section=1. Acesso em 03.jan .2019.

VEJA. O Amazonas está sendo reflorestado. Edição nº 77, de 25/02/1970. São Paulo: Abril, 1970. P. 15. Acervo Digital. Disponível em:

https://acervo.veja.abril.com.br/\#/edition/34478?page=1\&section=1. Acesso em: 03.jan. 2019.

VEJA. Transamazônica: A prática da epopéia. Edição nº 104, de 02/09/1970. São Paulo: Abril, 1970. P. 28-30. Acervo Digital. Disponível em

https://acervo.veja.abril.com.br/\#/edition/34451?page=1\&section=1. Acesso em: 10.jan .2019.

VEJA. Metade do Brasil quer metade do seu imposto de renda. Edição $\mathrm{N}^{\circ} 132$, de 17/03/1971. São Paulo: Abril, 1970. P. 08. Acervo Digital. Disponível em:

https://acervo.veja.abril.com.br/\#/edition/34423?page=8\&section=1. Acesso em: 03.jan .2019.

VEJA. Conheça o Paraíso Verde. Edição No 136, de 14/04/1971. São Paulo: Abril, 1971. P. 54-55. Acervo Digital. Disponível em:

https://acervo.veja.abril.com.br/\#/edition/34419?page=1\&section=1. Acesso em: 03.jan.2019. 
VEJA. Examinando as obras. Edição No 161, de 06/10/1971. São Paulo: Abril, 1971. P. 25. Acervo Digital. Disponível em https://acervo.veja.abril.com.br/\#/edition/34394?page=1\&section=1. Acesso em: 05.jan .2019.

VEJA. O grande desafio deste século pede mais que sua coragem. Pede seu imposto de renda. Edição No 165, de 03/11/1971. São Paulo: Abril, 1971. P. 16-17. Acervo Digital. Disponível em https://acervo.veja.abril.com.br/\#/edition/34390?page=18\&section=1. Acesso em 07.jan.2019.

VEJA. A Amazônia tem dono. Você é um deles. Edição No 181, de 23/02/1972. São Paulo: Abril, 1972. P. 42-43. Acervo Digital. Disponível em:

https://acervo.veja.abril.com.br/\#/edition/34374?page=42\&section=1. Acesso em: 03.jan.2019.

VEJA. Meio Caminho Andado. Edição nº 213, de 04/10/1972. São Paulo: Abril, 1972. P. P. 1819. Acervo Digital. Disponível em:

https://acervo.veja.abril.com.br/\#/edition/34341?page=18\&section=1. Acesso em: 03.jan.2019.

VEJA. A luta para fabricar bois. Edição No 266, de 10/10/1973. São Paulo: Abril, 1973. P. 66-78. Acervo Digital. Disponível em:

https://acervo.veja.abril.com.br/\#/edition/34287?page=66\&section=1. Acesso em:

03.jan.2019.

WEBER, Max. Ensaios de Sociologia. 5 ed. Organização e Introdução de H.H. Gerth e C. Wright Mills. Tradução de Waltensir Dutra. Rio de Janeiro: Guanabara, 1982.

WEBER, Max. Economia e Sociedade. Fundamentos da Sociologia Compreensiva. Vol. 1. Brasília: Editora UNB. São Paulo: Imprensa Oficial, 2003. 